\title{
Hormonal Regulation of Normal Voice Production in Adolescence, a Review
}

\author{
Mette Pedersen ${ }^{1 *}$, Anders Overgård Jønsson², and Christian Frederik Larsen ${ }^{3}$ \\ ${ }^{1}$ Medical Centre, $\varnothing$ stergade, Copenhagen, Denmark \\ ${ }^{2}$ University of Copenhagen, Faculty of Health and Medical Sciences, Blegdamsvej, Copenhagen, Denmark \\ ${ }^{3}$ Copenhagen Business School, Solbjerg Plads, Frederiksberg, Denmark
}

*Corresponding author: Mette Pedersen, Medical Centre, Østergade, Copenhagen, Denmark, E-mail: m.f.pedersen@dadlnet.dk

Received: 07 Oct, 2020 | Accepted: 22 Oct, 2020 | Published: 23 Oct, 2020

Citation: Pedersen M, Jønsson AO, Larsen CF (2020) Hormonal Regulation of Normal Voice Production in Adolescence, a Review. J Clin Case Stu 5(4): dx.doi.org/10.16966/2471-4925.207

Copyright: (C) 2020 Pedersen M, et al. This is an open-access article distributed under the terms of the Creative Commons Attribution License, which permits unrestricted use, distribution, and reproduction in any medium, provided the original author and source are credited.

\begin{abstract}
Voice production is discussed based on the hormonal regulation of adolescence. The reason for the overview is that voice production is an integrated part of pathology-in many multi-handicapped cases, voice production is extremely important. In a search made by the Royal English Society of Medicine only few studies of adolescence included voice production, so we supplemented the overview with references from other trials. Testosterone is related to the lowering of voice in males, and oestradiol to the change in females. The interesting prediction function of serum hormone binding globulin $(\mathrm{SHBG})$, for change in the fundamental frequency $\left(\mathrm{F}_{0}\right)$ during reading in adolescence, is elucidated. Not only the lowering of the $F_{0}$ but also a widening of the frequencies used during speech is seen. The lowest tone (in the voice profiles) is related to the hormonal development. Other androgens and oestrogens are discussed. The hormonal development of voice production is regulated from the hypothalamus probably related to growth hormone. Input is made mainly from the posterior superior temporal gyrus, insula, and the supplementary motor area to the primitive integrative vocalisation centre in the motor cortex. All these findings are important in the future, using advanced voice analysis and artificial intelligence methods to understand pathology.
\end{abstract}

Keywords: Voice production; Development; Adolescence; Hormones; Puberty

\section{Introduction}

Adolescence is a challenging time of voice change, normally, and in pathology, where lack of capability of voice production hinders social function. The understanding of normal hormonal changes is essential to help diagnose voice problems in pathology. Therefore, we tried to make an overview of hormonal- and adolescence research, focusing on where voice production science could be connected.

Technical methods for measuring voice production include high speed films combined with analysis programs, e.g. Glottal Analysis Tools (GAT). Convolution networks analysis of high speed films with 4000 pictures per second is used in the clinical setting as well as optical coherence tomography [1-3]. These methods with high amounts of input information should be related to hormonal and other biological measurements in adolescence, to help treat many developmental disorders that include voice production.

The aim of the overview is to confirm the state of the art, of the connections between exact measurement of development of voice production, and adolescence related hormonal development-to open for supplementary understanding of voice and brain function in pathology. Voice production measurements should be an integrated part in pathology e.g. genetic malformations including cochlear implants $[4,5]$ as well supplement the arbitrary definition of pubertal voice break, as it is made in research even now a days by self-evaluation of clients.

\section{Methods}

With Medline, Embase and hand search the amount was small of hormonal research papers that included voice production studies in adolescence, as searched by the librarians at the Royal society of medicine, UK. Table 1 shows the search methods for the systematic review of "Voice, Hormonal and Gender Development". The search resulted in 9 papers, therefore, we included our own intensive search of other papers on adolescence, often based on reference lists in studies of other subjects, that could be relevant for understanding development in adolescence even if the papers were without voice measurements.

\section{Results}

\section{Studies of brain and genetics related to hormonesand voice production in adolescence}

Of the 9 papers found by the systematic search for Voice, Hormonal, and Gender Development, there were only 4 usable papers [6-9]. Two other papers were used as adjacent studies [10,11].

Our subsequent hand search was mostly made, using reference lists from papers on adolescence. These papers on hormonal development did not include the development of voice production, but since the systematic search returned limited results ( 9 papers), these were used to illustrate the problem surrounding voice production. 
The brain development of voice production related areas in adolescence is mostly genetic. It all begins from the nasal placode wherefrom GnRH (gonadotropin releasing hormone) neurons migrated to hypothalamus [12,13] as shown in Figure 1.

Figure 1 shows the central activation of GnRH neurons by leptin, considered necessary for normal pubertal development. The nasal placode, and development of GnRH neurons have been considered a causal mechanism as stimulating factors on KNDy neurons (Kisspeptin, neurokinin B, dynorphins). The genes involved are included in the figure. The neuropeptide alfa-MSH plays a key role in energy homeostasis by mediating the action of leptin and may have a central role to the metabolic control of puberty. From the hypothalamus, at the medio basal area, the arcuate nucleus (ARC), the pituitary gland is stimulated, also by the GnRH-PG (Gonadotropin Releasing Hormone-Prostaglandin), the reaction depending on the GnRH-R-(Receptors). Follicle stimulating and luteinizing hormones stimulate the ovaries in girls, and in boys the production of Leydigcells' production of testosterone, stimulating puberty. In girls the Anti-Müller hormone (AMH) for egg reserve and inhibin level of hindering FSH production in the pituitary are regulated in balance with $\mathrm{E}_{2}$ (oestradiol), stimulating puberty. Extrinsic factors (EDC) and body mass index (BMI) have an impact on the development.

McCarthy [14] described in her book, the development of sex and the brain in animals in details but admits that animal studies are not

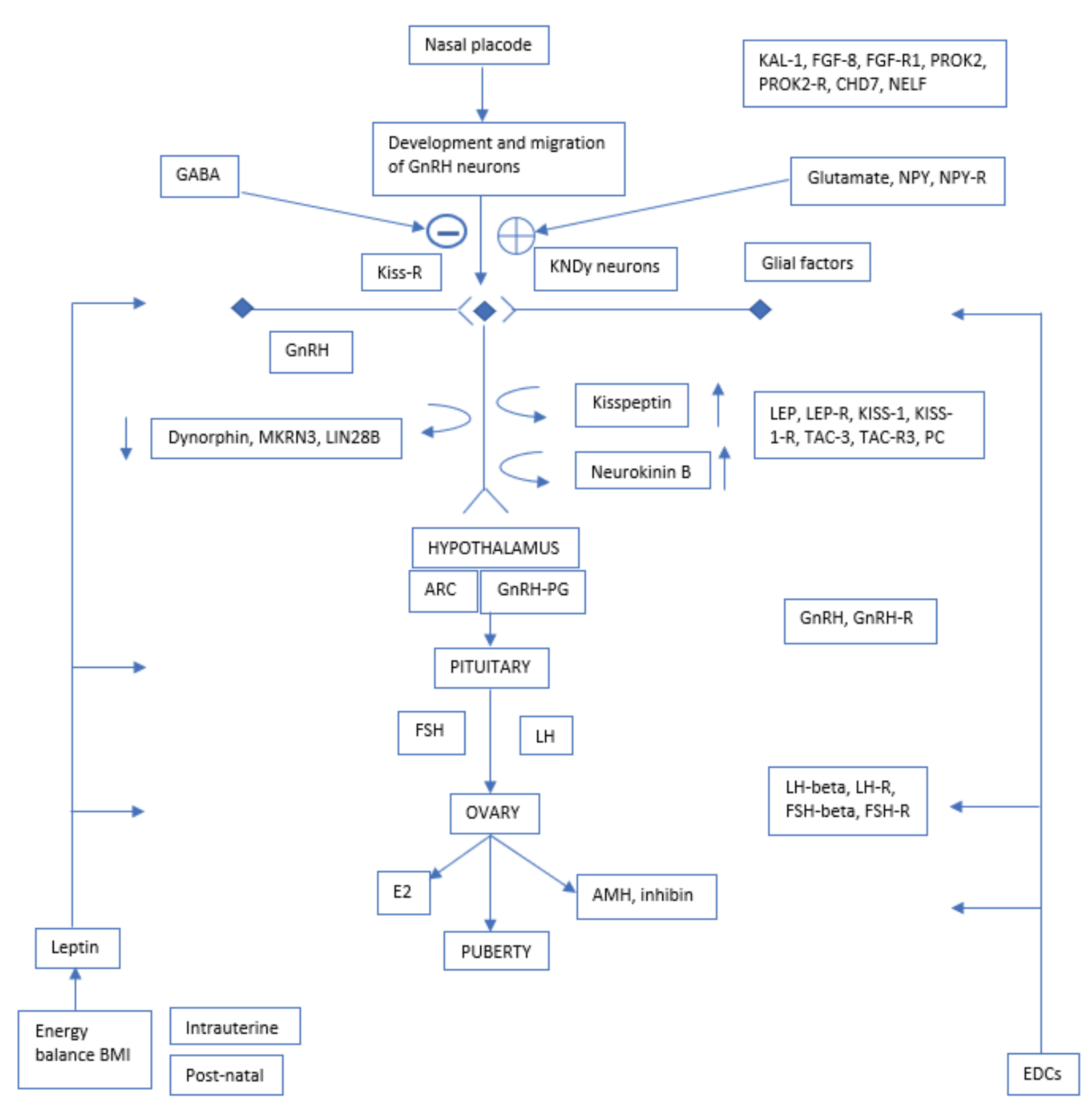

Figure 1: Presents an overview of the genes involved in puberty regulation with hypothalamus in the centre. The development starts from the nasal placode in the foetus with development and integration of $\mathrm{GnRH}$ neurons (gonadotropin releasing hormone expressing neurons). 
Table 1: Search Strategy

Databases: Embase ${ }^{\circledR}$, MEDLINE $^{\circledR}$ (run 24/03/20)

\begin{tabular}{|c|c|c|}
\hline Set\# & Searched for & Results \\
\hline S8 & s7 not ti (transgender* or "trans men") & $214^{*}$ \\
\hline S7 & (s1 or s2 or s3) and (s4 or s5 or s6) and (la (english) or abany (yes)) and pd (2010-2020) & 222 \\
\hline S6 & $\begin{array}{l}\text { MJEMB.EXACT (“sex hormone”) OR MJEMB.EXACT (“hormone”) OR MJEMB.EXACT.EXPLODE (“hormone action”) OR } \\
\text { MJEMB.EXACT.EXPLODE ("sex hormone") }\end{array}$ & 327531 \\
\hline S5 & MJMESH.EXACT.EXPLODE (“Hormones”) OR MJMESH.EXACT.EXPLODE ("Sexual Development”) & 910938 \\
\hline S4 & $\begin{array}{l}\text { ti,ab((hormone }\left[{ }^{*} 1\right] \text { or hormonal or testosteron* or }[* 2] \text { strogen* or progesteron*) near/5 (develop* or puberty or } \\
\text { chang* or increase* or decreas* or maturation or adolescen*)) }\end{array}$ & 264432 \\
\hline S3 & MJEMB.EXACT (“vocal cord”) OR MJEMB.EXACT (“voice”) & 18716 \\
\hline S2 & MJMESH.EXACT.EXPLODE (“Voice”) OR MJMESH.EXACT (“Vocal Cords”) & 14166 \\
\hline S1 & ti,ab ((voice $\left.{ }^{*} 1\right]$ or vocal*) near/5 (chang* or develop*)) & 12589 \\
\hline
\end{tabular}

*The search strategy retrieved a number of references that were then hand searched to find the most relevant. The details of 9 references have been provided in accordance with your original request.

directly useable in voice studies of humans. This is also the case for Perrodin C, et al. [15], Zaqout SI and Al-Hussain SM [16], Xie Y and Dorsky RI [17] discuss the development of brain incl. hypothalamus across vertebrate species. The knowledge of human subcortical development is summarized by Abbott, et al.[18]

Wierenga et al. [19] show that changes in testosterone level were related to development of pallidum, accumbens, hippocampus and amygdala volumes in males and caudate and hippocampal volumes in females. The modeling interaction between pubertal maturation and chronological age seemed to be sex specific. Etchell A, et al. [20] admit that sex differences in childhood language development is unclear-in a review of 46 published studies they conclude that sex differences may be more prominent during certain developmental stages due to different rates of maturation between the sexes. They admit that more research is needed to understand the influence of sex hormones and developmental stages. They notice that sex differences in brain structure and function do not necessarily lead to differences in task performance, and evidence for sex differences of development are limited, when present, sex differences often interact with a variety of factors such as age and task.

The important definition of puberty stages $1-5$ is referring to Marshall and Tanner with voice change in boys between stage 2 and 4 [21]. Styne DM [22] made a thorough overview of puberty phenomena referring to Tanner and including genetics, hormones etc, voice is not discussed. This is also the case in the survey of puberty by Busch AS, et al. [6]. The author state here that puberty cannot be perceived as a solitary event, they discuss basic genetic changes, and hormonal changes as well as brain changes as earlier referred to, in this paper. The concepts are of 1 . adrenarche (of production DHEAS and and rostenedione in the adrenals) 2. thelarche, breast development 3. menarche, beginning of menstruation, 4. pubarche, pubic hair development, 5. godanarche, secondary sex characteristics. Styne DM [22] also discusses prepubertal values of serum hormone binding globulin (SHBG) and oestron/oestradiol with general guidelines for prepubertal values. They point out that the pubertal stages are determined by hormones, of which most of the circulating oestradiol and testosterone is associated with SHBG and that prepubertal boys and girls have equal concentration of SHBG.
The mutational voice is between 12,5 and 14 years of age. The vocal folds in males at 16 years of age are $18-24 \mathrm{~mm}$ long with a fundamental $\left(\mathrm{F}_{0}\right)$ of $130 \mathrm{Hertz}$. In girls, 16 years of age, the vocal folds are $15-20 \mathrm{~mm}$ long and the fundamental frequency $\left(\mathrm{F}_{0}\right)$ is 220-225 [23]. At 6-12 years the vocal folds have two layers, at 16 years the vocal folds have three layers, which is documented with optical coherence tomography [24]. Table 2 shows the relations between voice parameters and androgens in boys and table 3 shows the relation between voice parameters and androgens/oestrogens in girls.

Busch AS, et al. [6] still recently described "voice break" recurring at 13,6 years (13,5-13,8 years of age) The voice breaks was self-evaluated and corresponded to testis size $11,8 \mathrm{~mm}(4-20 \mathrm{~mm})$ and genital stage 3 (stage 2-5). In pathology voice production related to puberty should be much more focused upon, as earlier mentioned e.g. in cochlear implants and in many other developmental disorders e.g. Turner syndrome $[25,26]$.In adults there seems now to be an acceptance of the functional connectivity of among others, periaqueductal grey (PAG) with core limbic system and laryngeal cortico-motor structures during human phonation, divided in volitional and non-volitional phonation [27].

Figure 2 describes how input and ongoing voice modulation is from the posterior superior temporal gyrus (PSTG) as well as from the supplementary motor area (SMA) and Insula. Output from the primitive integrative vocalization centre (VOC) as shown by Penfield and Roberts [31] is described. Black lines in figure 1 are for the direct pathway via the corticobulbar pathway and the cerebellum (CBL) bilaterally. Grey lines show the pathway from VOC to the cingulate, Amygdala Nucleus (AM) Periaqueductal Grey (PAG) the pons and the reticular area in the medulla with input to Nucleus Ambiguous (NA) on both side of the brain. Human emotionally based vocalisation and volitional voice production have shown more integration than previously proposed- It should be noted that reflexive as well as learned voice production-not involuntary speech-have a common system.

Holstege G, et al. [28] underline that only humans can speak because, via the lateral components of the volitional or somatic motor system, they are able to modulate vocalization into words and sentences by activation of the prefrontal area, PAG, and caudal medullary Nucleus Retro Ambiguous (NRA). NRA is the only cell group that has direct 
Table 2: Shows the relations between voice parameters and androgens in boys.

\begin{tabular}{|c|c|c|c|c|c|}
\hline Age & (years) & 8.7-12.9 & 13.0-15.9 & 16.0-19.5 pr yr. & \% change \\
\hline No of boys & & 19 & 15 & 14 & \\
\hline Serum testosterone & (n mol/l) & 0.54 & 10.5 & 18,9 & 68 \\
\hline Dihydrotestosterone & (n mol/l) & 0.18 & 1.21 & 1.57 & 37 \\
\hline Free testosterone & (n mol/l) & 0.007 & 0.14 & 0.33 & 77 \\
\hline Sexual hormone binding globulin & (n mol/l) & 134 & 66 & 45 & -16 \\
\hline Delta 4 androstene dione & (n mol/l) & 0.54 & 1.17 & 2.5 & 24 \\
\hline Dehydro epi andro sterone sulfate & (n mol/l) & 1400 & 4100 & 5900 & 25 \\
\hline Testis volume & $(\mathrm{ml})$ & 2,3 & 13 & 20 & 36 \\
\hline Fundamental frequency & $(\mathrm{Hz})$ & 237 & 184 & 125 & -11 \\
\hline Voice range & (semitones) & 3.7 & 4.8 & 5 & 3.9 \\
\hline Phonetogram area & $\left(\mathrm{cm}^{2}\right)$ & 19 & 28 & 34 & 9.2 \\
\hline Lowest biological tone & $(\mathrm{Hz})$ & 158 & 104 & 72 & -12 \\
\hline
\end{tabular}

Geometrical average of hormonal, pubertal and vocal parameters for boys grouped according to pre-pubertal, pubertal, post-pubertal age and the annual change in these parameters in \%. (Phonetogram area: $1 \mathrm{~cm}^{2}=32$ semitones $\left.\times \mathrm{dB}(\mathrm{A})\right)[49]$.

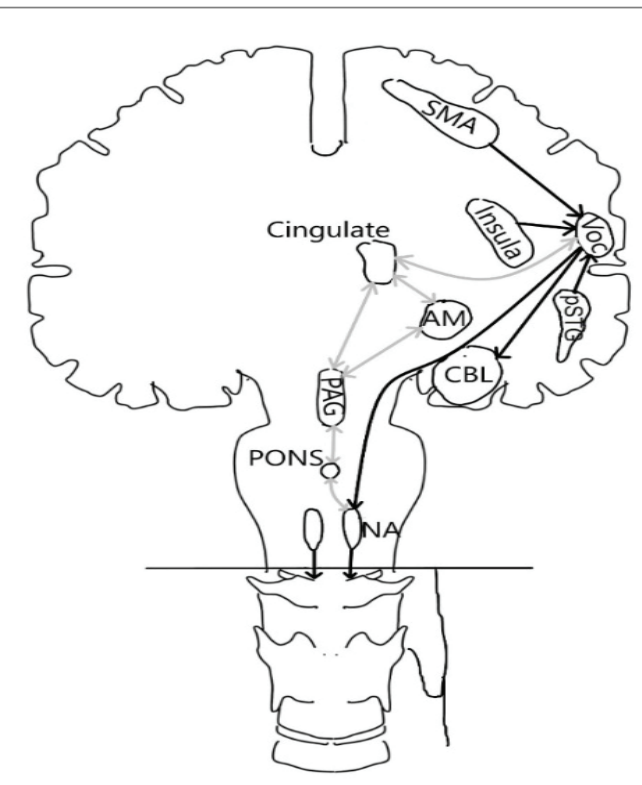

Figure 2: Input and ongoing modulation is from the posterior superior temporal gyrus (pSTG under the VOC) as well as from the supplementary motor area (SMA) and Insula. Output from the primary integrative vocalisation centre (VOC). Black lines are the direct pathway via the corticobulbar pathway and the cerebellum (CBL) bilaterally. Grey lines show the pathway from VOC to the cingulate, nucleus amygdalae (AM), periaqueductal Gray (PAG), the pons and the reticular area in the medulla with input to nucleus ambiguous (NA) on both sides of the brain. From there to the vagus nerve.

access to the motor neurons involved in vocalizations. On a planned large-scale chart for developmental changes in the brain, a focus will be on the pubertal period from 9-17 years of age, and structural plus functional activity will be compared with pubertal hormones and pubertal development [29]. Vasung L, et al. [30] conclude that it remains unclear how among others metabolic demands influence the development.

\section{Acoustics related to hormones and voice productionin ado- lescence}

There was a change of understanding of the human voice with the vowel research made by Peterson and Barney [31]. Studies have been made of the role of formant overtone maxima in children [32]. An important approach is the study of the development of resonances in speech and singing as well [33-35]. The sex hormone receptors in vocal folds have been focused upon by Nacci A, et al. [10] but were seldom found. The authors speculate that the changes of voice according to gender throughout life might be linked with a different expression of some growth factor in the laryngeal tissue and that this expression might in turn be influenced by hormonal variation. Interesting is a study from Sato K, et al. [36] showing that the vocal fold mucosa, unphonetic, without voice, two cerebral palsy children (7 and 12 years old) did not have a vocal ligament, lamina propria appeared as a uniform structure, vocal fold stellate cells synthesized fewer extracellular matrix substances such as fibrous protein and glycosaminoglycan. 


\section{Hormones and adrenarche}

Adrenarche encloses the change of the outer layers of adrenals related to pubic and axillary hair. Guran T, et al. [37] measured the age and DHEA-S secretion in healthy children at adrenarche, where DHEA-S concentration over $108,4 \mathrm{~nm} / \mathrm{L}(40 \mu \mathrm{g} / \mathrm{mL})$ were regarded as adrenarche at 8 years of age in girls and 7 years for boys. Dörr HG, et al. [38] confirm that DHEA-S were higher in Turner girls without growth hormone therapy, but that the time of adrenarche were the same with or without hormone therapy. Whittle S, et al. [39] focus on adrenarche timing on brain function,in the study of early adrenarche defined by high DHEA-S independent of age of effects on brain function. 83 children, mean age 9,53 (SD 0,34) hereof, 43 female were examined, and a higher DHEA level was associated with decreased affect related activity in the mid-cingulate cortex in the whole sample, and in a number of cortical and sub cortical regions in females. Higher DHEA levels were also associated with increased externalizing psychological symptoms in females that were partly mediated by posterior-insula activation. The author suggests that timing of adrenarche is an important moderator of affect related brain function. Barendse MEA, et al. [40] confirm that adrenarche changes in the brain structures are prior to godanarche. In a longitudinal study of DHEA/ DHEA-S and testosterone on fMRI at 9 years, high DHEA suggested negative association with white matter microstructure. Higher values were also related to anxiety symptoms through an effect on amygdala and inferior frontal gyrus. Testosterone was related to the development of white matter.

Development of voice production should be much more exact than self-reported voice break to compare to other parts of body development and pathology [6]. There are many developmental disorders, where voice production is part of the handicap [5]. New focus on voice development was made in treated adrenal cortical tumours. In 9 adults and 10 adolescents female, $\mathrm{F}_{0}$ was reduced to 132 Hertz in 1 and F0 to $165 / 168 \mathrm{~Hz}$ respectively in two subjects. The majority had normal $\mathrm{F}_{0}$, from 189 to $245 \mathrm{~Hz}$ [41].

\section{Adjacent studies}

There are some aspects of early development that influence the voice related hormonal situation in adolescent youngsters: Especially the "mini-puberty" around birth and growth hormones. A problem is that a lot of research on hormones is on primates/ non-humans, which means that even if some results are common- when it comes to human voice, they can probably not be used. For the "mini-puberty" around perinatal life it is important to understand that peripheral hormones in blood serum are regulators in a transitory hormone surge that is comparable in its extent to puberty [42-44]. Borysiak A, et al. [11] noted that $\mathrm{F}_{0}$ properties were correlated to average serum levels of bio available oestradiol $\left(\mathrm{E}_{2}\right)$ (mean E2/SHBG and testosterone/mean testosterone across the second month of life. They interpreted the results as indication of $\mathrm{E}_{2}$ influence on viscoelastic properties of vocal folds.

In rats $[8,9]$ a study was made on the role of the vocal folds, especially the extracellular matrix (ECM) in vocal fold lamina propria. The hyaluronic acid decreased in ovariectomized rats. The collagen- 1 was lowered, this was also the case of collagen- 3 later in the observational period. Elastin was less dense in the same rats. They suggest that the vocal folds are an oestrogen sensitive target organ.

The study of Hodges-Siemon CR, et al. [45] and her group on testosterone and vocal parameters in 91 adolescent male indicated that males in better energetic conditions (BMI-for-age residuals from Tanner-specific growth curves) have higher testosterone and lowered voice even controlling for age. Testosterone given to females is a wellknown risqué of voice lowering. Wuntakal $\mathrm{R}$, et al. [46] refer to some

Table 3: Shows the relation between voice parameters and androgens/oestrogens in girls.

\begin{tabular}{|c|c|c|c|c|c|}
\hline Age & (years) & 8.7-12.9 & 13.0-15.9 & $16.0-19.8$ & Significance \\
\hline Total number & & 18 & 12 & 11 & \\
\hline Oesterone (E1) & pmol & 57 & 104 & 123 & $* *$ \\
\hline Oestradiol (E2) & pmol & 73 & 135 & 108 & \\
\hline Total testosterone & $\mathrm{nmol}$ & 0.5 & 0.76 & 0.94 & \\
\hline Free testosterone & $\mathrm{nmol}$ & 0.006 & 0.037 & 0.009 & \\
\hline Oesterone sulphate (E1SO4) & pmol & 732 & 1924 & 2342 & $* *$ \\
\hline DHEAS & $\mathrm{nmol}$ & 3210 & 3700 & 7200 & $* *$ \\
\hline Androstendione & $\mathrm{nmol}$ & 1.44 & 3.28 & 3.43 & $*$ \\
\hline Sex hormone binding globulin (SHBG) & $\mathrm{nmol}$ & 153 & 130 & 123 & \\
\hline Menarche & & +4 & +9 & +11 & \\
\hline Pubic hair stage & & $1-4$ & $2-5$ & $4-6$ & \\
\hline Mamma development stage & & $1-4$ & $2-5$ & 5 & \\
\hline Fundamental frequency in continuous speech & $\mathrm{Hz}$ & 256 & 248 & 241 & \\
\hline Tone range in continuous speech & Semitones & 3.7 & 4.2 & 5.2 & $* *$ \\
\hline Tone range in singing & Semitones & 23 & 30 & 38 & \\
\hline Phonetographic area & $\mathrm{cm}^{2}$ & 17.3 & 21.8 & 28.3 & $* *$ \\
\hline Phonetogram lowest tone & $\mathrm{Hz}$ & 166 & 156 & 145 & $*$ \\
\hline Phonetogram middle tone & $\mathrm{Hz}$ & 429 & 409 & 413 & \\
\hline Phonetogram highest tone & $\mathrm{Hz}$ & 1136 & 1105 & 1263 & \\
\hline
\end{tabular}

Geometrical averages of hormonal, pubertal and vocal parameters for girls grouped according to pre-pubertal, pubertal, post-pubertal age. The relative standard deviation lay between $11 \%$ and $140 \%$. (Significance of the differences between the groups: $p<0.01 \mathrm{xx} ; \mathrm{p}<0.05 \mathrm{x}$ ). Cm $\mathrm{m}^{2}$ conversion factor: $1 \mathrm{~cm}^{2}=32$ semitones $\times \mathrm{dB}(\mathrm{a})[49]$. 
voice effects of LHRH agonists given for ovarian cancer. Zacharin $M$ [47] has an overview of treatment of secondary hypogonadism of treated severe illness in childhood and adolescents since many children now survive chronic illnesses.

\section{Prediction by hormones of voice production change in ado- lescence}

Shirtcliff EA, et al. [48] has made an overview of hormonal change in puberty where it was shown that a picture-based interview combined with testosterone, DHEA and physical exam gave better predictive values. SHBG had a predictive significance of F0 change in boys of $\mathrm{p}<0.05$, in girls the widening of the tone range of the fundamental frequency in semitones (F0range) with electroglottography during reading of a standard text and E1So4 measureshad predictive values of $\mathrm{p}<0.05$ [49].

Gaidano G, et al. [50] found that mean values of SHBG binding capacity, both for dihydrotestosterone and testosterone were significantly higher in prepubertal subjects. The binding capacity of SHBG is a result of a pool of proteins which modifies pubertal evolution. Rosner W, et al. [51] discus SHBG as a cell regulator, they demonstrate an additional mode of action on steroid hormones, one that does not require that the steroid interacts with a receptor. Kim $\mathrm{MR}$, et al. [52] measured SHBG which decreases markedly during early puberty. They found that $50 \mathrm{~nm} / \mathrm{L}$ in stage Tanner 2 were significantly different to Tanner stage 1 and that free androgen index (FAI=testosterone/SHBG) could even better differentiate the onset of puberty. The decrease of SHBG coincidence with a significant increase in total body weight and body mass index.

Simo R, et al. [53] describe how sex hormone binding globulin (SHBG) is produced and secreted by the liver into the bloodstream where it binds sex steroids and regulates their bioavailability, by limiting their diffusion into their target tissue. Further research is needed to elucidate the molecular mechanism that could explain the sexual dimorphism regarding the plasma SHBG levels. Laurent MR, et al. [54] comment that the in-vivo physiological role of circulating SHGB remains unclear, transgene mice expressing a human SHBG transgene were used in their study. SHGB is an interesting factor in prediction of voice change in puberty in Tanner stage 2-4 due to its' multifactorial tissue effects.

\section{Discussion}

Results of the systematic library search gave only 4 studies that included hormonal and voice production in adolescence

The voice break was self-evaluated in the hormonal studies. On the other hand, voice production development in puberty in Phoniatrics 1 [5] is described without hormones. With the social demands including voice production (voice performance) e.g. multi-handicapped patients are in a bad situation. We have the tools of high speed films and GAT, deep learning, and optical coherence tomography to analyze detailed sound and vocal fold phenomena in large scales. It is possible to compare the huge data amount with deep learning. This could give a more nuanced understanding of deviant voice behavior. And optical coherence tomography could at the same time give information of deviant tissue function.

\section{Fundamental frequency $\left(\mathrm{F}_{0}\right)$, tone range and the lowest tone}

In adolescence it is easy to measure the $\mathrm{F} 0$ in a well-defined situation, e.g. measured during reading of a standard text or with standard counting and relate to testosterone/oestradiol. It is not only the mean
$\mathrm{F}_{0}$ that is changing, also the frequency variation is expanding (the tone range) as it can be seen in the voice profile [5]. The lower tone becomes lower, which we know, is related to androgens and oestrogens (Table 2 and 3) [49]. This is used by singing teachers in choirs for prediction of pubertal change of voice production.

\section{Prediction of the change of voice production in adolescence}

The measurement of testosterone and oestradiol correlate to the change of $\mathrm{F}_{0}$ at the age of 13-15.9 years. Serum hormone binding globulin (SHBG) is significantly a predicting factor of F0 change in adolescence in boys. This allows us to speculate whether the change of voice could be related to a broader symptom complex [49-54]. Another way to get further understanding of the hormonal control of voice production might be to relate, as a standard not only to puberty stages 1-5 but also to the time of appearance of adrenarche, pubarche, godanarche, menarche and thelarche. This could specify relations of hormones and voice production usable also in pathology [24].

\section{Conclusion}

A systematic search was made on Voice, Hormonal, and Gender Development, which unfortunately only returned 9 papers, of which 4 were related to the subject. Additional hand search resulted in papers on hormonal changes and adolescence, but without voice production. Some papers were informative. The normal genetic regulation of hormones in adolescence is presented. Hormonal development and especially the Serum Hormone Binding Globulin (SHBG) has a predicting role for the development of voice production in adolescence which is not fully understood. In the future combined hormonal and updated online high speed measures of voice production can give a much better understanding of voice production development-eventually combined with optical coherence tomography and analyzed with neural networks. Especially in pathology, mostly genetic multi-handicaps' syndrome patients could be better understood.

\section{Author Contributions}

Conceptualization: MP. Data curation: MP, AOJ. Formal analysis: MP, AOJ. Funding acquisition: MP. Methodology: MP, AOJ Visualization: MP, CL, AOJ. Writing - original draft: MP. Writing review \& editing: MP, CL, AOJ.

\section{References}

1. Fehling MK, Grosch F, Schuster ME, Schick B, Lohscheller J (2020) Fully automatic segmentation of glottis and vocal folds in endoscopic laryngeal high-speed videos using a deep Convolutional LSTM Network. PLoS One 15: 1-29.

2. Maryn $\mathrm{Y}$, Verguts $\mathrm{M}$, Demarsin $\mathrm{H}$, van Dinther J, Gomez $\mathrm{P}$, et al. (2019) Intersegmenter Variability in High-Speed LaryngoscopyBased Glottal Area Waveform Measures. Laryngoscope 1-8.

3. Pedersen $M$, Agersted A, Akram B, Mahmood S, Jønsson A, et al. (2016) Optical coherence tomography in the laryngeal arytenoid mucosa for documentation of pharmacological treatments and genetic aspects: a protocol. Adv Cell Mol Otolaryngol 4.

4. Kumar P, Sanju HK, Singh NK (2020) Neural representation of consonant-vowel transition in individuals with cochlear hearing loss and auditory neuropathy spectrum disorder. Eur Arch Oto-RhinoLaryngology 277: 2739-2744.

5. am Zehnhoff-Dinnesen A, Wiskirska-Woznica B, Neumann K, Nawka $\mathrm{T}$ (2020) editors. Phoniatrics I. Springer Berlin Heidelberg. 
6. Busch AS, Hollis B, Day FR, Sørensen K, Aksglaede L, et al. (2019) Voice break in boys temporal relations with other pubertal milestones and likely causal effects of \{BMI\}. Hum Reprod 34: 1514-1522.

7. Howard DM, Welch GF, Himonides E, Owens M (2019) The Developing Female Chorister Voice: Case-Study Evidence of Musical Development. J Voice 33: 516-525.

8. Kim JM, Kim JH, Shin S-C, Park GC, Kim HS, et al. (2020) The Protective Effect of Echinochrome A on Extracellular Matrix of Vocal Folds in Ovariectomized Rats. Mar Drugs 18: 77.

9. Kim JM, Shin S-C, Park G-C, Lee J-C, Jeon YK, et al. (2020) Effect of sex hormones on extracellular matrix of lamina propria in rat vocal fold. Laryngoscope 130: 732-740.

10. Nacci A, Fattori B, Basolo F, Filice ME, Jeso K De, et al. (2011) Sex Hormone Receptors in Vocal Fold Tissue: A Theory about the Influence of Sex Hormones in the Larynx. Folia Phoniatr Logop 63: 77-82.

11. Borysiak A, Hesse V, Wermke P, Hain J, Robb M, et al. (2017) Fundamental Frequency of Crying in Two-month-old Boys and Girls: Do Sex Hormones During Mini-puberty Mediate Differences? J Voice 31: 128 E21-128.E28.

12. Sultan C, Gaspari L, Maimoun L, Kalfa N, Paris F (2018) Disorders of puberty. Best Pract Res Clin Obstet Gynaecol 48: 62-89.

13. Cho H-J, Shan Y, Whittington NC, Wray S (2019) Nasal Placode Development, $\{\mathrm{GnRH}\}$ Neuronal Migration and Kallmann Syndrome. Front Cell Dev Biol 7.

14. McCarthy MM (2017) Sex and the Developing Brain Second Edition. Colloq Ser Dev Brain 6: 141

15. Perrodin C, Kayser C, Logothetis NK, Petkov Cl (2014) Auditory and Visual Modulation of Temporal Lobe Neurons in Voice-Sensitive and Association Cortices. J Neurosci 34: 2524-2537.

16. Zaqout SI, Al-Hussain SM (2013) Functional and Anatomical Features of the Dorsal Column Nuclei in Mammals and Lower Animals. Am J Med Biol Res 1: 23-27.

17. Xie Y, Dorsky RI (2017) Development of the hypothalamus: conservation, modification and innovation. Development 144: 1588-1599.

18. Abbott R, Burkitt E (2015) Child development and the brain. Bristol University Press.

19. Wierenga LM, Bos MGN, Schreuders E, vd Kamp F, Peper JS, et al. (2018) Unraveling age, puberty and testosterone effects on subcortical brain development across adolescence. Psychoneuroendocrinology 91: 105-114.

20. Etchell A, Adhikari A, Weinberg LS, Choo AL, Garnett EO, et al. (2018) A systematic literature review of sex differences in childhood language and brain development. Neuropsychologia 114: 19-31.

21. Brook CG (2019) Brook's Clinical Pediatric Endocrinology. Dattani MT, Brook CGD, editors. Brook's Clinical Pediatric Endocrinology. Wiley.

22. Styne DM (2019) Puberty. In: Pubertal Suppression in Transgender Youth. Elsevier 13-24.

23. Sataloff RT (2017) Voice Science. $2^{\text {nd }}$ ed. Sataloff RT, editor. San Diego, CA, USA: Plural Publishing.

24. Garcia JA, Benboujja F, Beaudette K, Guo R, Boudoux C, et al. (2016) Using attenuation coefficients from optical coherence tomography as markers of vocal fold maturation. Laryngoscope 126: E218-E223.
25. Torppa $\mathrm{R}$, Huotilainen $\mathrm{M}$, Leminen $\mathrm{M}$, Lipsanen J, Tervaniemi $\mathrm{M}$ (2014) Interplay between singing and cortical processing of music: a longitudinal study in children with cochlear implants. Front Psychol

26. Menke LA, Sas TCJ, van Koningsbrugge SHL, de Ridder MAJ, Zandwijken GRJ, et al. (2011) The Effect of Oxandrolone on Voice Frequency in Growth Hormone-Treated Girls With Turner Syndrome. J Voice 25: 602-610.

27. Ludlow CL (2015) Central Nervous System Control of Voice and Swallowing. J Clin Neurophysiol 32: 294-303.

28. Holstege G, Subramanian HH (2016) Two different motor systems are needed to generate human speech. J Comp Neurol 524: 15581577.

29. Somerville LH, Bookheimer SY, Buckner RL, Burgess GC, Curtiss SW, et al. (2018) The Lifespan Human Connectome Project in Development: A large-scale study of brain connectivity development in 521 year olds. Neuroimage 183: 456-468.

30. Vasung L, Turk EA, Ferradal SL, Sutin J, Stout JN, et al. (2019) Exploring early human brain development with structural and physiological neuroimaging. Neuroimage 187: 226-254.

31. Stokes MA (2014) 99.8 percent accuracy achieved on Peterson and Barney (1952) acoustic measurements. J Acoust Soc Am 136: 2083.

32. Cartei V, Reby D (2013) Effect of Formant Frequency Spacing on Perceived Gender in Pre-Pubertal Children's Voices. Nusbaum H, editor. PLoS ONE 8: e81022.

33. Wolfe J, Garnier M, Smith J (2009) Vocal tract resonances in speech, singing, and playing musical instruments. HFSP J 3: 6-23.

34. Fuchs M, Meuret S, Thiel S, Täschner R, Dietz A, et al. (2009) Influence of Singing Activity, Age, and Sex on Voice Performance Parameters, on Subjects Perception and Use of Their Voice in Childhood and Adolescence. J Voice 23: 182-189.

35. Döllinger M, Dubrovskiy D, Patel R (2012) Spatiotemporal analysis of vocal fold vibrations between children and adults. Laryngoscope 11: $2511-2518$

36. Sato K, Umeno H, Nakashima T, Nonaka S, Harabuchi Y (2012 Histopathologic Investigations of the Unphonated Human Child Vocal Fold Mucosa. J Voice 26: 37-43.

37. Guran T, Firat I, Yildiz F, Bulut IK, Dogru M, et al. (2014) Reference values for serum dehydroepiandrosterone-sulphate in healthy children and adolescents with emphasis on the age of adrenarche and pubarche. Clin Endocrinol (Oxf) 82: 712-718.

38. Dörr HG, Penger T, Marx M, Rauh M, Oppelt PG, et al. (2019) Adrenarche and pubarche in girls with turner syndrome during growth-promoting therapy with human growth hormone. BMC Endocr Disord 9.

39. Whittle S, Simmons JG, Byrne ML, Strikwerda-Brown C, Kerestes R et al. (2015) Associations between early adrenarche, affective brain function and mental health in children. Soc Cogn Affect Neurosci 10: $1282-1290$

40. Barendse MEA, Simmons JG, Byrne ML, Patton G, Mundy L, et al. (2018) Associations between adrenarcheal hormones, amygdala functional connectivity and anxiety symptoms in children. Psychoneuroendocrinology 97: 156-163.

41. Grisa L, Leonel ML, Gonçalves MIR, Pletsch F, Sade ER, et al. (2012) Impact of Early Postnatal Androgen Exposure on Voice Development. PLosone 7: e50242. 
42. Wermke K, Hain J, Oehler K, Wermke P, Hesse V (2014) Sex hormone influence on human infants sound characteristics: melody in spontaneous crying. Biol Lett 10: 20140095.

43. Wermke K, Quast A, Hesse V (2018) From melody to words: The role of sex hormones in early language development. Horm Behav 104 206-215.

44. Quast A, Hesse V, Hain J, Wermke P, Wermke K (2016) Baby babbling at five months linked to sex hormone levels in early infancy. Infant Behav Dev 44: 1-10.

45. Hodges-Simeon CR, Gurven M, Gaulin SJC (2015) The low male voice is a costly signal of phenotypic quality among Bolivian adolescents. Evol Hum Behav 36: 294-302.

46. Wuntakal R, Seshadri S, Montes A, Lane G (2016) Luteinising hormone releasing hormone (LHRH) agonists for the treatment of relapsed epithelial ovarian cancer. Cochrane Database Syst Rev CD011322.

47. Zacharin M (2015) Pubertal induction in hypogonadism: Current approaches including use of gonadotrophins. Best Pract Res Clin Endocrinol Metab 29: 367-383.

48. Shirtcliff EA, Dahl RE, Pollak SD (2009) Pubertal Development: Correspondence between Hormonal and Physical Development. Child Dev 80: 327-337.
49. Pedersen M (2008) Normal Development of Voice in Children. Springer Berlin Heidelberg.

50. Gaidano G, Berta L, Rovero E, Valenzano C, Rosatti P (1980) Dynamics of the binding capacity of plasma sex hormone binding globulin (SHBG) for testosterone and dihydrotestosterone during puberty. Clin Chim Acta 100: 91-97.

51. Rosner W, Hryb DJ, Khan MS, Nakhla AM, Romas NA (1991) Sex hormone-binding globulin: Anatomy and physiology of a new regulatory system. J Steroid Biochem Mol Biol 40: 813-820.

52. Kim MR, Gupta MK, Travers SH, Rogers DG, Lente F Van, et al. (1999) Serum prostate specific antigen, sex hormone binding globulin and free androgen index as markers of pubertal development in boys. Clin Endocrinol (Oxf) 50: 203-210.

53. Simó R, Sáez-López C, Barbosa-Desongles A, Hernández C, Selva DM (2015) Novel insights in SHBG regulation and clinical implications. Trends Endocrinol Metab 26: 376-383.

54. Laurent MR, Hammond GL, Blokland M, Jardí F, Antonio L, et al (2016) Sex hormone-binding globulin regulation of androgen bioactivity in vivo: validation of the free hormone hypothesis. Sci Rep 6. 